\title{
Pengaruh Teknik Relaksasi Nafas Dalam terhadap Intensitas Nyeri pada Persalinan Kala I Fase Aktif di PMB Y Karawang
}

\author{
Imelda Diana Marsilia ${ }^{\mathbf{1}}$, Nina Tresnayanti ${ }^{\mathbf{2}}$ \\ ${ }^{1,2}$ Sekolah Tinggi Ilmu Kesehatan Mitra RIA Husada \\ Email: imeldadianamarsilia@gmail.com
}

Submitted : 07/04/2021

Accepted: 10/09/2021

Published: 15/09/2021

\begin{abstract}
Mothers who are facing the labor process will feel pain related to uterine contractions, various ways have done to reduce pain, namely by non-pharmacological techniques, including deep breathing relaxation, massage, changes in the mother's position so that labor can run safely and comfortably. This study aims to determine the effect of deep breath relaxation techniques on pain intensity in the active phase of labor. This research is a quasi-experimental design approach method pre test and post test. The sampling technique used accidental sampling as many as 28 mothers had birth in July - August BPM Y Karawang. The results of the data normality statistical test used the Shapiro-Wilk test. Data analysis using the Wilcoxon test obtained signed rank $p$ value $0.0000<0.05$. The conclusion are that there are an effect of deep breath relaxation techniques on decreasing the pain intensity of the active phase of labor. The suggestion of this study is that deep breath relaxation techniques can be recommended as a complementary tearpie and applied to relieve pain during labor, so that labor can run smoothly.
\end{abstract}

Keywords: labor pain, relaxation techniques, stage I active phase

Abstrak

Ibu yang menghadapi proses persalinan akan merasakan nyeri sehubungan dengan kontraksi uterusnya, berbagai cara dilakukan untuk mengurangi rasa nyeri, yaitu dengan teknik non farmakologi antara lain relaksasi nafas dalam, massage, perubahan posisi ibu agar persalinan bisa berjalan dengan aman dan nyaman. Penelitian ini bertujuan untuk mengetahui pengaruh teknik relaksasi nafas dalam terhadap intensitas nyeri pada persalinan kala I fase aktif. Penelitian ini adalah quasi eksperiment metode pendekatan desain pre test dan post test. Teknik pengambilan Sampel menggunakan accidental sampling sebanyak 28 ibu bersalin pada bulan Juli - Agustus BPM Y Karawang. Hasil Uji Statistik Normalitas data menggunakan uji Shapiro-Wilk. analisis data menggunakan uji Wilcoxon.di peroleh signed rank $p$ Value $0,0000<0,05$. Kesimpulan ada pengaruh teknik relaksasi nafas dalam terhadap penurunan intensitas nyeri persalinan kala I fase aktif. Saran penelitian ini diperlakuan teknik relaksasi nafas dalam dapat di rekomendasikan sebagai tearpi komplementer dan diterapkan untuk meredakan rasa nyeri selama persalinan, sehingga persalinan dapat berjalan dengan lancar.

Kata Kunci: kala I fase aktif, nyeri persalinan, teknik relaksasi

\section{PENDAHULUAN}

Persalinan merupakan hal yang paling ditunggu-tunggu oleh para ibu hamil, sebuah waktu yang sangat menyenangkan, namun disisi lain merupakan hal yang mendebarkan. tetapi persalinan juga di sertai rasa nyeri yang membuat kebahgian yang di dambakan diliputi kebahagiaan yang di dambakan diliputi rasa takut dan cemas. Beberapa penelitian menunjukan bahwa pada masyarakat primitive. mengalami persalinan yang lebih lama dan nyeri, sedangkan masyarakat yang telah maju bersalin tanpa rasa nyeri dan sebagian besar $(90 \%)$ persalinan disertai rasanyeri (Elly S, 2017).

Kala I persalinan normal, nyeri bisa diakibatkan oleh kontraksi involunter otot uteri. Kontraksi cenderung dirasakan di punggung bawah pada awal persalinan. Sensasi nyeri melingkari batang tubuh 
bawah, yang mencakup abdomen dan punggung. Kontraksi umumnya berlangsung sekitar 45 sampai 90 detik. Ketika persalinan mengalami kemajuan, intensitas setiap kontraksimeningkat, menghasilkan intensitas nyeri yang lebih besar (Astried, 2017). Nyeri persalinan dapat dikendalikan dengan 2 metode yaitu farmakologis dan non-farmakologis. Metode penghilang rasa nyeri secara farmakologis adalah dengan menggunakan obat-obatan kimiawi, sedangkan metode non farmakologis dilakukan secara alami tanpa menggunakan obat-obatan kimiawi yaitu dengan melakukan teknik relaksasi yang mencakup relaksasi napas dalam, relaksasi otot, masase, musik dan aromaterapi (Elly S, 2017).

Menurut para responden banyak yang mengatakan bahwa nyeri hanya dapat di sembuhkan dengan cara mengkonsumsi obat seperti obat Asmefenamic, Parasetamol dan lain - lain, ini pernyataan yang kurang tepat karena nyeri dapat di turunkan dengan terapi non-farmakologi seperti terapi mordalitas atau komplemeter salah satunya adalah menggunakan teknik relaksasi nafas dalam (Kalola, Ribka, Novita, 2018).

Hasil penelitian yang dilakukan oleh Astried Mulyani (2017), menyebutkan bahwa teknik relakssai pernafasan sebelum di lakukan teknik relaksasi dengan jumlah 17 responden, Nyeri ringan 1 orang 5,9\%. Nyeri sedang 7 orang $41,2 \%$. Nyeri berat terkontrol 9 orang 52,9\%. teknik relaksasi pernafasan sesudah dilakukan teknik relaksi. Tidak nyeri 4 orang $23,5 \%$. Nyeri ringan 12 orang $70,6 \%$. Nyeri sedang 1 orang $5,9 \%$. di ketahui sekala nyeri sebelum dilakukan teknik relaksi pernafasan keseluruhan responden mengalami nyeri berat kemudian setelah dilakukan terapi mengalami penurunan intensitas nyeri dari berat ke nyeri sedang (Astried, 2017). Penelitianyang sama juga dilakukan Taqwin (2018) di dapatkan 15 responden bahwa intensitas nyeri sebelum di lakukan teknik nafas dalam di PMB di Praktik Bidan Mandiri Anatapura bahwa Nyeri ringan 0 orang $0 \%$. Nyeri Sedang 11 orang $73.3 \%$. Nyeri berat 4 orang $26.7 \%$. Nyeri yang paling hebat 0 orang $0 \%$. Sesudah dilakukan karakteristik tingkat nyeri persalinan kala I fase laten di praktik bidan mandiri anatapura. Nyeri ringan 12 orang $80 \%$. Nyeri Sedang 3 orang $20 \%$. Nyeri Berat 0 oarang $0 \%$. Nyeri yang paling hebat 0 orang $0 \%$. diketahui bahwa teknik relaksasi nafas dalam dapat menurunkan nyeri dengan signifikan terbukti dengan jumlah responden tanpa mengkonsumsi obat nyeri dapat menurunkan dari skala 5 menurun menjadi 3 (Kalola, Ribka, Novita, 2018). Dan dari hasil wawancara bidan di PMB bidan Y tanggal 15 Februari 2020 terdapat 10 responden ibu nifas bahwa 7 (70\%) mengalami nyeri Berat, dan hanya $3(30 \%)$ ibu mengalami nyeri sedang saat persalinan. dan mereka mengatakan untuk mengatasi nyeri tersebut dengan cara beristirahat atau minum obat.

Hasil wawancara dengan bidan di PMB belum menerapkan terapi nonfarmakologi dan praktik komplementer seperti teknik relaksasi nafas dalam sesuai dengan teori karena pasien di PMB cukup banyak sementara bidan yang bertugas masih kurang. selanjutnya bidan mendiskusikan pada pasien atau keluarga untuk melakukan terapi teknik relaksasi nafas dalam bertujuan penurunan nyeri persalinan tanpa menggunakan anastesi. Tujuan penelitian ini Untuk mengetahui Pengaruh Teknik Relaksasi Nafas dalam Terhadap Intensitas Penurunan Rasa Nyeri pada Ibu Bersalin kala I fase Aktif di PMB Y Karawang pada Tahun 2020.

\section{METODE PENELITIAN}

Penelitian ini merupakan quasi eksperiment. Desain pendekatan yang digunakan adalah pre-test dan post-test. Penelitian ini dilakukan bulan Juli- Agustus di PMB Y Karawang tahun 2020. Populasi 
penelitian ini adalah ibu bersalin di PMB Y Karawang Sebanyak 28 ibu. Sampel dalam penelitian di ambil menggunakan accidental sampling dengan jumlah sampel sebanyak 28 orang ibu. Pengumpulan data dalam penelitian ini dilakukan dengan instrument lembar observasi Skala nyeri NRS dan WB. Sebelum dilakukan terapi teknik relaksasi nafas dalam menilai sepintas kecemasan, dan ketakutan ibu menghadapi persalinan di ukur dengan Skala nyeri Numeric Rating Scale (NRS) dan Skala Wong-Baker Pain Rating Scale (WB) sebagai data pre-test. Selanjutnya di berikan terapi teknik relaksasi nafas dalam dengan cara merilekasasi dan membuat ibu tenang atur posisi ibu senyaman maka melanjutkan teknik nafas dalam dengan cara merileksasikan otot abdomen. Tepatkan satu atau dua tangan pada abdomen tepat di bawah tulang iga. meminta ibu untuk menarik nafas dalam melalui hidung, jaga mulut tetap tertutup hingga hitungan 1.2.3 selama inspirasi. Konsentrasi dan beritahu ibu setiap kontraksi rasakan seperi ada gelombanggelombang cinta dan kasih sayang terhadap ibu dan calon bayi, tetap kondisi rileks pastikan posisi punggung ibu tidak miring kiri/kanan dan bila terdapat kesulitan menaikan abdomen, Tarik nafas dalam dengan cepat, lalu nafas kuat lewat hidung. melakukan observasi pada responden selama 30 menit pertama, responden melakukan penaarik nafas dari hidung dalam waktu 3-5 detik, lalu menghembuskan nafas 3-5 detik pada kontraksi uterus. Kemudian pasien bernafas normal 1-2 menit, lalu menarik nafas dalam dengan mengempiskan rongga abdomen lalu mengeluarkan dari mulut dalam waktu 3-5 detik dengan kombinasi berdiri 10 menit, duduk 10 menit, dan berbaring di tempat tidur 10 menit (Ayuningsih, 2018).

\section{HASIL DAN PEMBAHASAN}

Analisa Univariat

Tabel .1Nilai Rata - rata Responden Sebelum dan Sesudah di lakukan Teknik Relaksasi Nafas Dalam menggunakan Instrumen Numeric Rating Scale (NRS) di PMB Y Karawang

\begin{tabular}{|c|c|c|c|c|}
\hline $\begin{array}{l}\text { Skala Nyeri } \\
\text { Persalinan } \\
\text { berdasarkan } \\
\text { Numeric Rating } \\
\text { Scale (NRS) }\end{array}$ & Mean & Median & SD & Min-Maks \\
\hline Sebelum Intervensi & 7.07 & 6.00 & 1.464 & $6-9$ \\
\hline Sesudah Intervensi & 3.96 & 3.00 & 1.427 & 3- 6 \\
\hline
\end{tabular}

Berdasarkan tabel 1 diketahui bahwa nilai rata - rata nyeri persalinan sebelum dilakukan intervensi menggunakan Numeric Rating Scale (NRS) adalah 7.07. dengan nyeri terendah adalah 6. dan nyeri tertinggi adalah 9. Nilai rata - rata setelah dilakukan intervensi adalah 3.96. dan nyeri tersendah 3 . dan nyeri tertingi 6 . 
Tabel 2 Nilai Rata - rata Responden Sebelum dan Sesudah di lakukan Teknik Relaksasi Nafas Dalam menggunakan Instrumen Wong-Baker Pain Scale Di PMB Y Karawang 2020

\begin{tabular}{lcccc}
\hline $\begin{array}{l}\text { Skala Nyeri } \\
\text { Persalinan } \\
\text { berdasarkan }\end{array}$ & Mean & Median & SD & Min-Mak \\
$\begin{array}{l}\text { Wong-Baker Pain } \\
\text { Scale (WB) }\end{array}$ & & & & \\
\hline $\begin{array}{l}\text { Sebelum } \\
\text { Intervensi }\end{array}$ & 7.21 & 8.00 & .995 & $6-8$ \\
\hline $\begin{array}{l}\text { Sesudah } \\
\text { Intervensi }\end{array}$ & 2.86 & 2.00 & 1.008 & $6-8$ \\
& & & &
\end{tabular}

Tabel 3 Analisa Numeric Rating Scale (NRS) Pengaruh Teknik Relaksasi Nafas Dalam Terhadap Intensitas Nyeri Pada Persalinan Kala 1 Fase Aktif di PMB Y Karawang 2020

\begin{tabular}{lc}
\hline Nyeri Persalinan & $\begin{array}{c}\text { Asymp. Sig. (2- } \\
\text { tailed) }\end{array}$ \\
\hline Sebelum Intervensi & 0.000 \\
\hline Sesudah Intervensi & 0.000 \\
\hline
\end{tabular}

Tabel 3 hasil uji statistik pada penelitian ini menggunakan Uji Wilcoxon menunjukan bahwa intensitas skala nyeri persalinan Pre-tes, Post-tes teknik relaksai nafas dalam $(N R S)$ Sebelum Intervensi didapatkan hasil $\mathrm{p}=0,000$. dengan taraf signifikasi 0,05 jika nilai $\mathrm{p}$ lebih besar dari 0,05 maka hipotesis nol diterima dan jika nilai $\mathrm{p}$ lebih kecil dari 0,05 maka hipotsis nol di tolak. Hasil Uji Wilcoxon menunjukan nilai p value lebih kecil dari $0,05(0,000<0,05)$.

Tabel .4 Analisa Wong-Baker Pain Rating Scale Pengaruh Teknik Relaksasi Nafas Dalam Terhadap Intensitas Nyeri Pada Persalinan Kala 1 Fase Aktif di PMB Y Karawang 2020

\begin{tabular}{lc}
\hline \multicolumn{1}{c}{ Nyeri Persalinan } & $\begin{array}{c}\text { Asymp. Sig. (2- } \\
\text { tailed) }\end{array}$ \\
\hline Sebelum Intervensi & 0.000 \\
\hline Sesudah Intervensi & 0.000 \\
\hline
\end{tabular}

Berdasarkan tabel 4 hasil uji statistik pada didapatkan hasil $\mathrm{p}=0,000$. dengan taraf penelitian ini menggunakan Uji Wilcoxon signifikan $\mathrm{p}<0,05$. hal ini menunjukan menunjukan bahwa intensitas skala nyeri terdapat pengaruh terapi teknik relaksasi persalinan Pre-tes, Post-tes teknik relaksai terhadap intensitas nyeri pada persalinan kala nafas dalam (WB) Sebelum Intervensi I fase aktif. (Notoatmodjo S, 2018).

didapatkan hasil $\mathrm{p}$ value $=0,000$. Berdasarkan

nilai signifikan yang di dapat berarti nilai PEMBAHASAN

$\mathrm{p}<0,05$ yang menunjukan intensitas skala Tingkat Nyeri Persalinan Kala I Fase nyeri persalinan sebelum dan sesudah Aktif pada Ibu Bersalin sebelum dan intervensi berdistribusi normal. Begitu pula sesudah diberikan teknik relaksasi nafas hasil uji statistic berdasarkan Post-tes sesudah dalam NRS

dilakukan intervensi dengan skala (WB) 
Berdasarkan hasil instrument penelitian sebelum intervensi tingkat nyeri pada 28 responden ibu bersalin menggunakan skala Numeri Rating Scale (NRS) adalah $64.3 \%$ ibu bersalin Nyeri Sedang. $35.7 \%$ ibu bersalin Nyeri Berat. dan berdsarkan hasil instrument penelitian sesudah intervensi tingkat nyeri dilakukan perlakuan pada 28 responden ibu bersalin menggunakan skala Numeri Rating Scale $(N R S)$ adalah $67.9 \%$ ibu bersalin Nyeri Ringan, $32.1 \%$ ibu bersalin Nyeri sedang. maka dari hasil penelitian ini terdapat pengaruh terhadap tingkat nyeri pada persalinan menggunkan instrumen NRS.

Menurut Judha (2012), tingkat nyeri persalinan digambarkan dengan intensitas nyeri yang dipersiapkan oleh ibu saat proses persalinan. Intensitas rasa nyeri persalinan bisa ditentukan dengan cara menanyakan tingkat intensitas atau merajuk pada skla nyeri. Contohnya, menggunakan instrumen skala $0-10$ ( Skala Numeric). Nyeri persalinan merupakan kombinasi nyeri fisik akibat myometrium di sertai regangan segmen bawah rahim menyatu dengan kondisi psikologis ibu selama persalinan. Kecemasan kekhawatiran ibu seluruhnya menyatu sehingga dapat memperberat nyeri fisik yang sudah ada. Persepsi Nyeri yang semakin intensitas meningkatkan kecemasan ibu sehingga terjadi siklus takut-stres-nyeri dan seterusnya. Nyeri dipengaruhi oleh beberapa faktor fisiologis dan psikologis. Nyeri pada persalinan memiliki pola cukup dapat diprediksi. Lokasi nyeri berubah selama persalinan. Intensitas dan frekuensi nyeri meningkat seiringan dengan peningkatan kontraksi uterus (Syaripudin A.Nurhaeni, 2019).

Berdasarkan hasil observasi sebelum dilakukan intervensi kepada 28 responden ibu bersalin di PMB Y Karawang pada bulan Juli - Agustus 2020. peneliti memperkenalkan diri terlebih dahulu dan meminta izin dan menjelaskan prosedur kepada ibu bersalin untuk kesediaannya menjadi responden. dalam penelitian ini di berikan terapi teknik relaksasi nafas dalam selama proses persalinan.

Saat dilakukan perlakuan peneliti menilai kondisi pisikologis ibu. kecemasan, gelisah dan ketakutan di saat peroses menjelang pembukaan lengkap pada ibu Primigravida dan ibu multigravida dan tingkat nyeri ibu sebelum dilakukan intervensi banyak ibu yang mengeluh kesakitan. bagian pinggang terasa panas, Nyeri bagian bawah. kontraksi semakin kuat sehingga membuat abdomen ibu terjadi tekanan yang mengakibatkan nyeri. Peneliti menilai angka nyeri persalinan mulai dari pasien datang pembukaan $4 \mathrm{~cm}$ $6 \mathrm{~cm}$. meminta pasien untuk mengisi kuesionaer tingkat nyeri dari angka 0 - 10 . dan selajutnya melakukan intervensi pemberian teknik relaksasi nafas dalam terhadap intensitas nyeri persalinan kala I fase aktif PMB Y Karawang 2020.

Ketika sudah dilakukan intervensi maka peneliti melanjukan terapi teknik relaksasi nafas dalam kepada ibu bersalin namun sebelum dimulai peneliti meminta izin terlebih dahulu dan merileksasikan dan membuat tubuh merasa nyaman agar dapat menerima terapi teknik relaksasi yang akan diberikan pada ibu bersalin dimulai dari pembukaan aktif 6-10 cm dan pastikan identitas dan privasi klien. alat yang digunakan 1 buah bantal dan lembar observasi skala numeric rating scale dan skala wong baker pain rating scale. atur posisi ibu senyaman mungkin dan tempatkan ibu ditempat tidur atau kursi. dengan satu bantal. merileksasikan otot abdomen. tepatkan satu atau dua tangan pada abdomen tepat di bawah tulang iga ibu. meminta ibu untuk menarik nafas dalam melalui hidung, jaga mulut tetap tertutup hingga hitungan 1.2.3 selama inspirasi. konsentrasi dan membuat ibu nyaman dan beritahu ibu setiap kontraksi rasakan seperi ada gelombang - gelombang cinta dan kasih sayang terhadap ibu dan calon bayi. tetap kondisi rileks pastikan posisi punggung ibu 
tidak miring kiri/kanan dan bila terdapat kesulitan menaikan abdomen, Tarik nafas dalam dengan cepat, lalu nafas kuat lewat hidung. melakukan observasi pada responden selama 30 menit pertama, responden melakukan penaarik nafas dari hidung dalam waktu 3-5 detik, lalu menghembuskan nafas 3-5 detik pada kontraksi uterus. kemudian pasien bernafas normal 1-2 menit, lalu menarik nafas dalam dengan mengempiskan rongga abdomen lalu mengeluarkan dari mulut dalam waktu 3-5 detik dengan kombinasi berdiri 10 menit, duduk 10 menit, dan berbaring di tempat tidur 10 menit. yang dilakukan sesuai SOP yang ada.

\section{Aktif Ibu Bersalin sebelum dan sesudah diberikan teknik nafas dalam Wong Baker Paint Rating Scale}

Berdasarkan Hasil instrument penelitian sebelum intervensi tingkat nyeri pada 28 responden menggunakan skala wong baker pain rating scale $(W B)$. adalah 39.3 \% Lebih Nyeri. 60.7 \% Sangat Nyeri. Standar deviasi 0,995. Hasil penelitian tingkat nyeri sesudah dilakukan perlakuan pada responden menggunakan skala wong baker pain rating scale (WB). adalah $57.1 \%$ ibu bersalin Sedikit nyeri, $42.9 \% 12$ ibu bersalin sedikit lebih nyeri. maka dari hasil penelitian ini terdapat pengaruh terhadap tingkat nyeri pada persalinan menggunkan instrumen $W B$.

Menurut Sulistyo skala wong baker pain rating scale $(W B)$ untuk mengkaji nyeri terdiri 6 wajah dengan profil kartun yang menggambarkan wajah dari wajah yang sedang tersenyum ("Tidak Nyeri), kemudian secara bertahap meningkat menjadi wajah kurang bahagia ("Sedikit Nyeri"), wajah yang tidak bahagia ("Sedikit Lebih Nyeri"), wajah ("lebih Nyeri), wajah yang sangat sedih ("Sangat Nyeri), sampai wajah sangat ketakuatan ("Nyeri Sangat Hebat"). Skala deskriptif bermanfaat saja dalam upaya pengkajian tingkat keparahan nyeri, melainkan pula mengevaluasi perubahan kondisi klien (Syaripudin, 2019).
Prosedur yang dilakukan penelitian 28 ibu bersalin yang sebelum dan sesudah di berikan teknik relaksasi nafas dalam terhadap intensitas nyeri kala I Fase Aktif di PMB Y Karawang dilakukan bersamaan dengan Skala Numeric Rating Scale (NRS) dan Wong Baker pain Scale (WB). (Syaripudin A.Nurhaeni, 2019).

Nyeri persalinan merupakan kombinasi nyeri fisik akibat myometrium di sertai regangan segmen bawah rahim menyatu dengan kondisi psikologis ibu selama persalinan. Kecemasan kekhawatiran ibu seluruhnya menyatu sehingga dapat memperberat nyeri fisik yang sudah ada. Persepsi Nyeri yan semakin intensitas meningkatkan kecemasan ibu sehingga terjadi siklus takutstres-nyeri dan seterusnya. Nyeri pada persalinan dialami terutama selama kontraksi. Persepsi terhadap intensitas nyeri persalinan bervariasi bagi setiap perempuan. biasanya digambarkan nyeri paling ekstrim yang pernah di alami. Nyeri dipengaruhi oleh beberapa faktor fisiologis dan psikologis. Nyeri pada persalinan memiliki pola cukup dapat diprediksi. Lokasi nyeri berubah selama persalinan. Intensitas dan frekuensi nyeri meningkat seiringan dengan peningkatan kontraksi uterus (Riska R, 2019).

Dari hasil yang di dapatkan Teknik ralaksasi nafas dalam yang di berikan kepada ibu bersalin dapat membantu menurunkan tingkat nyeri persalinan dan menurunkan kecemasan dan ketidaknyamanan saat menghadapi persalinan serta mengatasi gejala fiologis yang pasien rasakan selama kala I Fase Aktif di PMB Bidan Y Karawang. Hal ini terbukti bahwa Teknik relaksasi dapat menurunkan intensitas skala nyeri persalinan setelah dilakukan penelitian eksperiemen oleh peneliti.

Begitu juga dengan hasil penelitian Juwita Sari (2019) yang mengatakan bahwa Pengaruh relaksasi pernafasan terhadap intensitas nyeri persalinan kala I fase Aktif 
di Klinik \& RB Zahira Karawang merupakan metode yang efektif dalam pemberiaan teknik relaksasi nafas dalam dapat berpengaruh terhadap persepsi nyeri dan kemampuan kontrol diri pada ibu tentang proses persalinan untuk mengurangi nyeri selama peroses persalinan. di dapatkan hasil uji statistic nilai $\mathrm{p}=0,000$ berdaasarkan nilai signifikan yang di dapatkan berti nilai $\mathrm{p}<0,05$ yang menunjukan intensitas nyeri berdistribusi normal.

Pengaruh Pemberian Teknik Relaksasi Nafas Dalam Terhadap Intensitas Nyeri Persalinan Pada Ibu Bersalin Kala I Fase Aktif Sebelum dan Sesudah Intervensi

Berdasarkan hasil penelitian yang sudah dilakukan menggunakan Skala Numeric Rating Scale (NRS), Terdapat nilai rata - rata skala nyeri persalinan adalah 7,07 dengan standar deviasi menunjukan angka 1.464. Setelah dilakukan perlakuan teknik relaksasi nafas dalam nilai rata - rata perbedaan adalah 3,96 standar deviasi 1.427. Terdapat nilai rata - rata perbedaan antara sebelum dan setelah adalah 3,11dengan standar deviasi 0,037. Hasil uji statistik $\mathrm{pValue}=0,000$ dengan taraf signifikan nilai pValue $<0,05$. Maka dapat di simpulkan berdasarkan instrument skala Nyeri Numeric Rating Scale (NRS) terdapat pengaruh relaksasi nafas dalam penurunan intensitas nyeri persalinan kala I Fase aktif (Astried dan Mulyani , 2017).

Diketahui rata-rata skala nyeri persalinan berdasarkan Wong Baker Face Pain Rating Scale (WBS) sebelum intervensi adalah 7.21 dengan standar deviasi 0,995. Setelah dilakukan intervensi terapi teknik relaksasi nafas dalam nilai rata - rata nyeri persalinan menjadi 2.86 dengan satandar deviasi 1,008. Terlihat perbedaan antara sebelum dan sesudah intervensi adalah 4,35. dengan standar deviasi 0,0013. Hasil ujia statistic didapatkan $\mathrm{P}$ Value $=$ 0,000 dengan taraf signifikan nilai $P$ Value $<0,05$, maka dapat disimpulkan berdasarkan instrument skala nyeri Wong
Baker Face Pain Rating Scale (WBS) terdapat Pengaruh Teknik Relaksasi Nafas Dalam Terhadap Intensitas Nyeri Pada Persalinan Kala I Fase Aktif.

Perlakukan teknik relaksasi nafas dalam banyak memberikan pengaruh terhadap respon adaptasi nyeri setelah dilakukan selama 30 menit. Hal ini dapat dibuktikan dengan hasil yang telah diperoleh. Teknik relaksai nafas dalam dapat mengurangi ketegangan, meningkatkan relaksasi fisik dan emosional.

Penurunan tingkat nyeri disebabkan ketika ibu inpartu yang merasakan nyeri dan melakukan relaksasi nafas dalam direspon oleh otak melalui korteks serebri lalu dihantarkan ke hipotalamus, hipotalamus melepaskan Corticotrophin Releasing Factor (CRF) lalu merangsang kelenjar pituitary untuk memberitahu medulla adrenal dalam meningkatkan produksi Prooploidmelanocortin (POMC) sehingga enkhepalin meningkat. Kalenjar pituitary menghasilkan hormone endorphin sebagai neurotransmitter yang dapat mempengaruhi suasana hati menjadi rileks. Peningkatan endhorpine dan enkhepalin menyebabkan tubuh menjadi rileks dan rasa nyeri berkurang (Marmi, 2016).

Hal ini sesuai dengan penelitian Taqwin (2018), yang mengatakan bahwa teknik relaksasi nafas dalam terhadap nyeri persalinan kala I fase aktif pada ibu bersalin di PMB Anatapura dapat menurunkan nyeri persalinan pada ibu bersalin. hal ini di buktikan berdasarkan adanya penurunan hasil posttest. oleh karena itu, teknik relaksasi nafas dalam dapat di gunakan sebagai intervensi dalam asuhan kebidanan ibu bersalin kala I untuk mengurangi nyeri. di dapatkan hasil uji statistic nilai $\mathrm{p}=0,000$ berdaasarkan nilai signifikan yang di dapatkan berti nilai $\mathrm{p}<0,05$ yang menunjukan intensitas nyeri berdistribusi normal (Kalola, Ribka, Novita, 2018). 
Perbandingan antara Penelitian Juwita S. Pengaruh Relaksasi Pernafasan Terhadap Intensitas Nyeri Pada Persalinan Kala I Fase Aktif Di Klinik \& Rumah Bersalin Zahira Karawang 2020.

Dari hasil penelitian ini pemberian teknik relaksasi nafas dalam sangat efektif untuk menurunkan Intensitas nyeri terhadap ibu bersalin kala I fase aktif berdasarkan pengukuran pada skala Numeric Rating Scale dan skala Wong Baker Pain Rating Scale. Perlu diperhatikan kembali bahwa sebelum melakukan pemberian ini paatikan ibu sudah di posisi yang nyaman dan ibu siap menggunakan teknik relaksasi nafas dalam.

Di samping itu Prosedur nafas dalam yang sudah dilakukan adalah pasien diatur posisi yang nyaman berbaring di tempat tidur, duduk, atau berdiri dan meminta untuk merileksasikan otot abdomen dan dua tangan pasien di perut di bawah iga. menarik nafas dalam melalui hidung. jaga mulut tetap tertutup hingga hitungan 1.2.3 selama inspirasi. konsentrasi dan membuat ibu nyaman dan beritahu ibu setiap kontraksi rasakan seperi ada gelombang gelombang cinta dan kasih sayang terhadap ibu dan calon bayi. tetap kondisi rileks pastikan posisi punggung ibu tidak miring kiri/kanan dan bila terdapat kesulitan menaikan abdomen, Tarik nafas dalam dengan cepat, lalu nafas kuat lewat hidung. melakukan observasi pada responden selama 30 menit pertama, responden melakukan penaarik nafas dari hidung dalam waktu 3-5 detik, lalu menghembuskan nafas 3-5 detik pada kontraksi uterus. kemudian pasien bernafas normal 1-2 menit, lalu menarik nafas dalam dengan mengempiskan rongga abdomen lalu mengeluarkan dari mulut dalam waktu 3-5 detik dengan kombinasi berdiri 10 menit, duduk 10 menit, dan berbaring di tempat tidur 10 menit. Maka terdapat perbandingan antara penelitian juwita dan hilda dari segi detik/menit melakukan teknik relaksasi nafas dalam (Syaripudin A.Nurhaeni, 2019).

Dalam Prosedur relaksi pernafasan yang sudah dilakukan penelitian Juwita $S$. (2019) adalah pernafasan diafragma yang mengacu pada pendataran kubah diafragma selama inpirasi yang mengakibatkan perbedaan abdomen bagian atas sejalan dengan desakan udara masuk selama inpirasi selama 30 meni. (Juwita S, 2019)

Penelitian ini sesuai dengan pernyatan penelitian Juwita S (2019) bahwa relaksasi pernafasan suatu metode non-farmakologi yang dapat di gunakan untuk mengurangi rasa nyeri persalinan. Metode pengukuran penelitian Juwita $S$ hanya menggunakan alat ukur Numeric Rating Scale tidak menggunakan Wong Baker Pain Scale maka dari pengkuran penelitian ini terdapat perbedaan antara penelitian ini dan Penelitian Juwita. relaksasi pernafasan ini juga mengurangi respon melawan atau menghindar seperti gemeteran. pada ibu inpartu menemukan bahwa tindakan ini akan melancarkan sirkulasi darah ibu dan dapat memberikan kenyamanan pada ibu. Relaksasi pernafasan dapat digunakan dalam asuhan kebidanan pada inpartu untuk membantu ibu mengurangi rasa nyeri persalinan tanpa efek samping pada ibu dan bayi. Perlu di perhatikan kenyamanan dan posisi ibu dalam penggunaan relaksasi pernafasan. Agar hasil yang di harapkan terdapat pengurangan nyeri tercapai dengan baik (Juwita S, 2019).

\section{SIMPULAN}

Adapun kesimpulannya dapat ditarik dari penelitian ini adalah sebagai berikut :Intensitas yeri persalinan kala I fase aktif sebelum diberikan teknik relaksasi nafas dalam berdasarkan Numeric Rating Scale sebesar 7.07. dan berdasarkan Wong Baker Pain Rating Scale sebesar 7.21.Intensitas nyeri persalinan kala I fase aktif sesudah dilakukan terapi teknik relaksasi nafas dalam berdasarkan Numeric Rating Scale sebesar 3.36. dan berdasarkan Wong Baker 
Pain Rating Scale sebesar 2.86.Pemberian teknik relaksasi nafas dalam sangat efektif untuk menurunkan Intensitas nyeri terhadap ibu bersalin kala I fase aktif berdasarkan pengukuran pada skala Numeric Rating Scale dan skala Wong Baker Pain Rating Scale.

\section{DAFTAR PUSTAKA}

Astried,Mulyani. (2017). Pengaruh aplikasi kontraksi nyaman terhadap perubahan intensitas nyeri pada persalinan kala 1 fase aktif di wilayah kerja puskesmas cibeureum kota tasikmalay.

Elly S. (2017). Pengaruh metode relaksasi pernafasan terhadap intensitas nyeri pada persalinan kala I fase aktif.

Taqwin. (2017). Pengaruh teknik relaksasi nafas dalam terhadap intensitas nyeri ibu bersalin kala 1 fase laten di praktik bidan mandiri anatapura.

Kalola, Ribka, Novita. (2018) .Pengaruh teknik relaksasi nafas dalam terhadap respon nyeri pada ibu inpartu kala $i$ fase aktif di puskesmas bahu kota manado ${ }^{2}$. Jurnal kesehatan :
Bare B, Smeltzer S. (2012). Buku Ajar Keperawatan Medikal Bedah Brunner \& Suddart (Alih Bahasa Agung Waluyo). Edisi 8 vol.3. Jakarta: EGC.

Syaripudin A.Nurhaeni. (2019). Manajemen Nyeri Persalinan dengan hipnobirting aplikasi kebidanan Komplementer. Yogyakarta: PT:Nuha Medika.

Ayuningsi. (2018). Kebidanan Komplementer Terapi Komplementer dalam Kebidanan. Yogyakarta: PT :Pustaka Baru Press.

Notoatmodjo S. (2018). Metodologi Penelitian Kesehatan. Jakarta : PT. Asdi Mahasatya.

Riska R. (2019). Pengaruh aromaterapi mawar terhadap penurunan nyeri ibu bersalin kala I fase aktif. Jakarta.

Juwita S. (2019). Pengaruh Relaksasi Pernafasan Terhadap Intensitas Nyeri Persalinan Kala I Fase Aktif di Klini \& RB Zahira. Jakarta 